\title{
From bones to columns: deciphering the codes of structures in nature and architecture
}

\author{
G. Berkin \\ Halic University Faculty of Architecture, Turkey
}

\begin{abstract}
Nature can lead us to new discoveries. Nature uses an ordered structure of patterns. Biologists have sought to understand the designs occuring in animals and plants for centuries. From their perspective, designers and engineers seek to generate designs for new problems. Recently, researchers have been adapting what they have learned from animal bones for use in architecture with a wide range of materials. This research represents a tendency of a growing field in science, called biomimetics. Biomimetics is the science of studying and emulating nature to solve mechanical and structural problems. Biomimetics may be defined as mimicking in human designs desirable features found in nature. The aim is to study the natural processes as a starting point, gain insights and then improve on their performance. This paper gives a short introduction to the current status of the discipline of biomimetics.
\end{abstract}

Keywords: biomimetics, cancellous bones, structural design, optimum section.

\section{Introduction}

Some designers earn their inspiration from nature: this could be structural or aesthetical. The transformation of structural elements is known as biomimetics. The roots of bio-mimetic words are biology, the study of living organisms, and mime comes from to mimic. Victor Papanek [1], a unique designer and lecturer has mentioned that designers must find analogies, using biological prototypes and systems for design approaches culled from such fields as ethology, anthropology, and morphology. Nature has great potential as means of structure and form for both designers and mechanical engineers. Designers and engineers often use analogies from biological systems to develop solutions for problems (e.g. they refer to nature's structural abilities for improving sections under heavy load). 
The literature in the designs derived from biology contains many case studies. Among recently made studies, Michael Helms et al. [2] reviewed several cases of biologically inspired designs in their article. They also shared their empirical study based on the academic projects. In cultures where humans are so intimate with animals, such analogies are seen in many buildings. Luigi Nervi, Antonio Gaudi and Santiago Calatrava were the pioneer designers of this kind. They were amazed with the ribbing function of bones and plant vessels and used this idea with reinforced concrete. An expressionist architect Paolo Portoghesi [3] has adduced lots of analogies between built environment and nature in his book Nature and Architecture. One of them sets a good example on the topic we are discussing. He states that the analogy between the Warren truss and vulture's metacarpal bone culminated as the topic of spatial reticular structures. Likewise industrial designers have inspired from animal skull bones while designing "Smart" car body. Recently, there also have been some attempts to transfer knowledge from one of the miracles of biology to engineering materials. Researchers found out that, a hole structure strengthens the metacarpal bone of horses. They designed a plate with a hole for load-bearing function with this concept.

\section{Optimum sections}

The response of a load bearing element to external forces is influenced by the geometric configuration of the section as well as the mechanical properties of the material. When a sample of structural material is under stress rather in tensile or compressive forces, its section shows a contraction or enlargement. So the structural element endures to strain together with its sectional geometry and
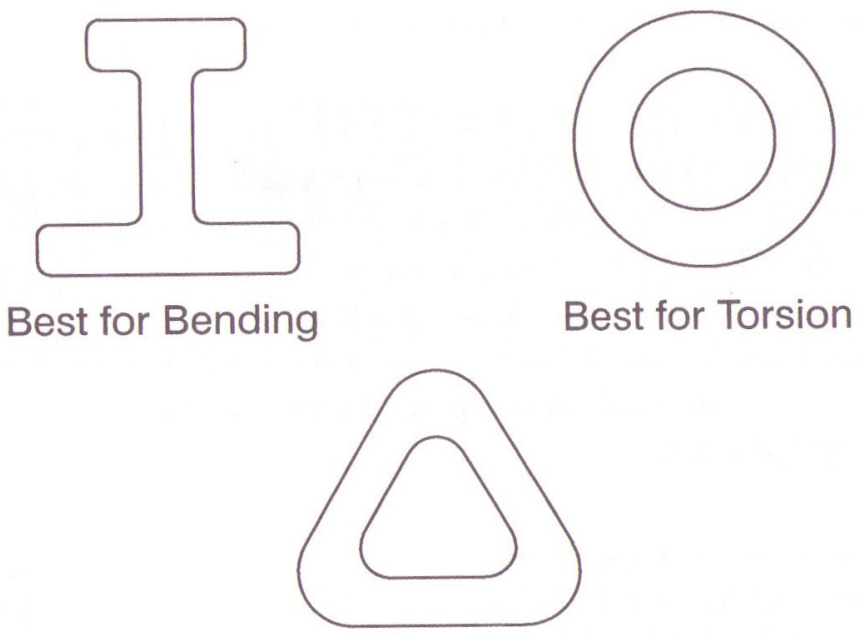

\section{Best for Combined Bending and Torsion}

Figure 1: Three sections of the same cross-sectional area. 
material properties. There are several calculations for determining the required cross-sectional dimensions of simple symmetrical beams to carry a given bending moment safely. One of them is the calculation of Moment of Inertia. This formula (1) is directly related with the height dimension of the sectional shape.

$$
\mathrm{I}=\mathrm{b} \cdot \mathrm{h}^{3} / 12
$$

In load bearing design different casting sections are preferred for different load conditions. For transverse bending, asymmetric 'I' sections give best use of material; for torsion, closed circular sections are best. For combined bending and twisting asymmetric closed sections are the optimum compromises [4]. At the end of the transformation process, the attained outcome could be reached by a simple gazing at nature. This optimized section of the bone structure has evolved and survived for thousand years and is there to be inspired by designers. In Figure 2, we see B as alligator femur, C as camel tibia and D as Pteranodon first
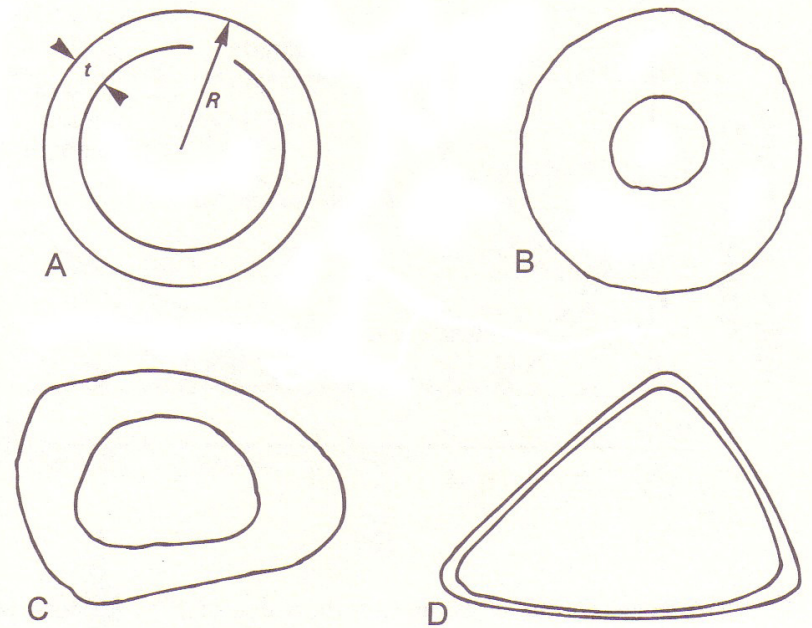

Figure 2: Shapes differ in the sections of bones related with load-bearing.

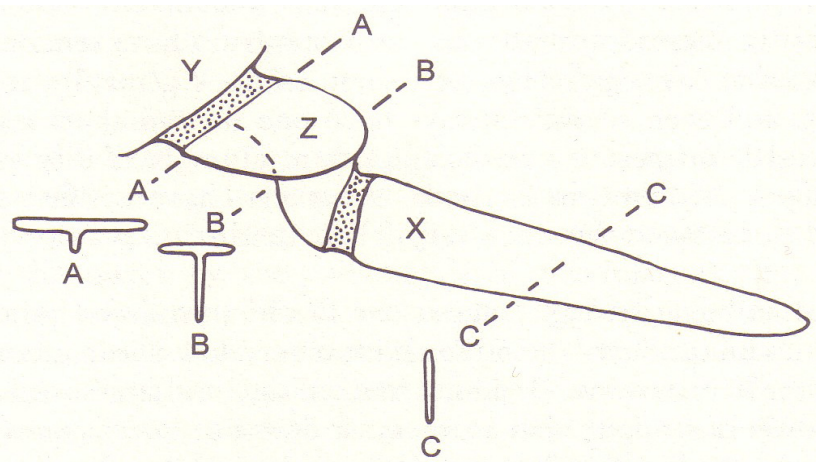

Figure 3: Tendon of a joint of the American lobster showing typical sections. 
phalanx. The minimum mass solution is directly related with the shape and geometry of the section [6].

\section{The internal structure of the bone}

Bones give shape, support, and protection to the body. All weight-carrying bones in general, the hollow space is filled with marrow, blood-vessels and other tissues; and amidst these living tissues lies a fine lattice-work of little inter-laced 'tabeculae' of bone, forming so-called 'cancellous tissue' [5]. In the internal structure of the bone, the cancellous bone acts as a compression member, while the ligaments act as tension-members. There is another feature of cancellous bone that may be important in extremis. The energy-absorbing ability of a cancellous bone is another feature of bones' structural ability [6]. Measured values for Young's modulus of bones vary somewhat from study to study, because different types of cancellous bone are being measured. For example researchers' records of maximum values differ from 280 and $350 \mathrm{MPa}$.

Much work has been done on the way in which the predominant direction of decussation is related to the local state of stress. For instance, in many early herbivores the tooth cusps are rather domed. Finite element analysis shows that such domes are likely to suffer tensile stresses acting in the horizontal direction (Hoop stresses), and therefore cracks are likely to run vertically...alternating layers of prisms seen with the help of scanning electron micrograph of the enamel of the incisor of a marmot. These layers are oriented in orthogonal sheets...There is no direction in which a crack can travel easily.

Mechanically important features of the architecture of cancellous bones are: their apparent density and fabric. Bones are presumed as nature's composite materials. The resemblance between composite materials and bone are the bone used the collagen as the matrix and the mineral as the fiber.

Bones act like fibrous composites. In a well-designed composite material any crack, as soon as it starts to travel, is forced to change its direction, or to pass into a void that makes it blunt-ended, or to give up the strain energy that could be driving it forward to the work required to pull strong fibers out of matrices, or to overcome a whole host of other features that all require an input of energy before the crack can travel further [6]. In bones, Hunter-Schreger bands cause difficulties for crack travel. When the crack reaches the decussation, it will split up and travel off in different directions. The crack cannot move far like this, and will tend to come to a halt.

It is an enigma that how bones should be built to ensure that they are strong enough to support animals of all sizes. Alexander [7] points out that there are geometric similarity, dynamic similarity, elastic similarity and stress similarities in different sizes of animal bones.

There are four types of bone, based on their shape: long, short, flat, and irregular. Bones contain cavities such as the large medullary cavity. These spaces are filled with either yellow or red marrow. There are two major types of bone, based on their histological structure. Compact bone is mostly solid matrix and cells. Cancellous bone consists of a lacy network of bone with many small, 
marrow-filled spaces as shown in Figure 4. Compact bone consists of lamella organized into sets of concentric rings with each set surrounding a central canal. Blood vessels that run parallel to the long axis of the bone are contained within the central canals. There are small voids in the lamella called canaliculi which give the osteon the appearance of having tiny cracks. Cancellous (spongy) bone consists of delicate interconnecting rods or plates of bone called trabeculae, which resemble the beams or scaffolding of a building. Like scaffolding, the trabeculae add strength to a bone. The spaces between the trabeculae are filled with marrow [8].

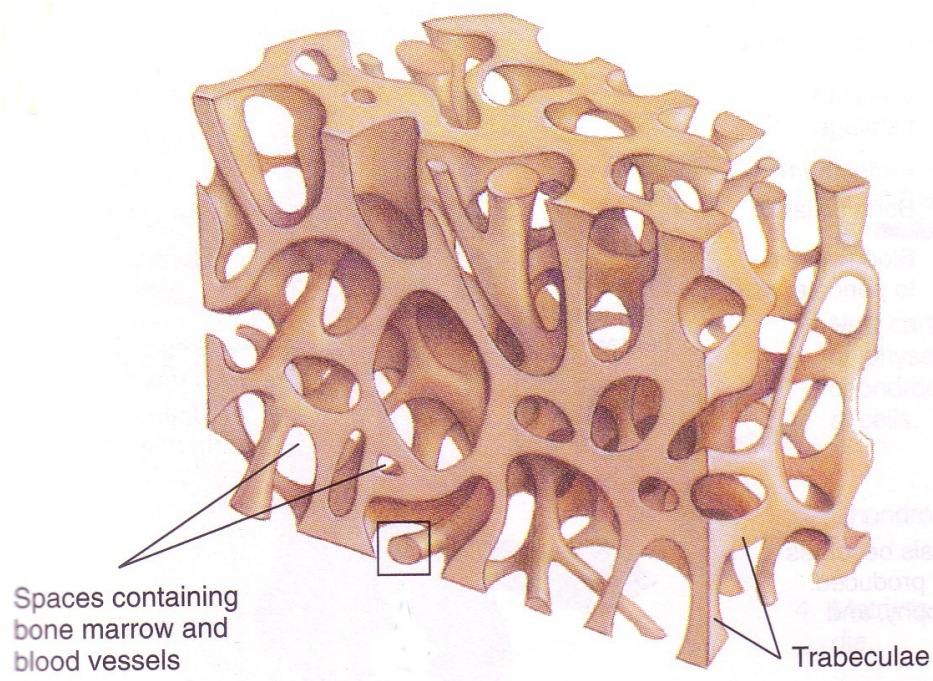

Figure 4: Cancellous trabeculae (beams of bone) spaces are filled with marrow.

\subsection{Designing for minimum mass}

The bone consists of $44 \%$ by weight of water and $56 \%$ solid matter. It is strong and hard due to impregnation of its ground substance with mineral salts, mainly calcium phosphate and calcium carbonate. The solid matter of the bone is composed of $67 \%$ inorganic material (mineral salts), and about 33\% organic matter consisting of cells, blood vessels, and cartilogous substance [8].

When the inorganic matter is removed from the bone (decalcification) The shape of the bone is kept but the result is a tough, flexible elastic substance. When the organic material is removed by heat, the rest of the bone becomes brittle. In the human skeleton there are different types of bones, such as long bones of the limbs, short bones of the wrist, and flat bones of the skull. In these bones there are two forms of bony tissue: The spongy and compact. The spongy tissue is more porous than compact and found on the inside and at the end of bones. Compact bone tissue is always found on the outside of the bones. 
Man has always derived ideas from the workings of nature. As design problems have become increasingly complex with the global proliferation of technology, mankind has become more and more alienated from direct contact with biological surroundings [1]. Among the structure of the living organisms we are astonished with the performance of the bones with regard to their lightness versus load-bearing features. The nature has decided how hollow should bones be. An indefinitely fat bone with vanishingly thin walls would be the least mass solution to the problem set by natural selection.

\section{Conclusion}

Bones are the designs of nature, built with load bearing and lightness features. Creatures of any kind uses bone structures with optimum sections so as to uplift, erect and move their bodies. Architects, industrial designers and mechanical engineers use this biological knowledge in their designs by means of guaranteed structural perfection. Experienced structural know-how saves time, energy and money when we compare to the trial and error procedure. By this way design concepts could find more easily an existence in realized objects.

\section{References}

[1] Papanek, V., Design For The Real World, Thames-Hudson, pp.188 1995.

[2] Helms, M., Vattam, S.S., Goel, A.K., Biologically Inspired Design: Process and Products, Design Studies, September 2009, Vol. 305, pp. 606-621.

[3] Portoghesi, P., Nature and Architecture, Skira, pp. 159, 2000.

[4] Ritchie and Simpson, Engineering Applications, pp. 175, 1998.

[5] Thompson, D., On Growth and Form, Canto, pp. 230, 1995.

[6] Currey, J.D., Bones Structure and Mechanics, Princeton University Press, pp. 156, 185, 200, 262, 2002.

[7] Alexander, R.M., Principles of Animal Locomotion, Princeton University Press, pp. 64, 2003.

[8] Seely, R.R., Stephens, T.D., Tate, P. Essentials of Anatomy and Physiology, McGraw-Hill, pp.112-114, 1999. 